\title{
Amount Recovered Infinity Predicted Normalized by Surface Area
}

National Cancer Institute

\section{Source}

National Cancer Institute. Amount Recovered Infinity Predicted Normalized by Surface

Area. NCl Thesaurus. Code C112227.

The cumulative amount recovered extrapolated to infinity, calculated using the predicted value of the last non-zero concentration, divided by the surface area. 